\title{
COMPELLING COMMENTS
}

\section{The American Academy of Dermatology Camp Discovery Goes Virtual}

\author{
Katie A. O'Connell, MS ${ }^{1}$, Haya Raef, $\mathrm{MS}^{2}$, David X. Gao, BA ${ }^{3}$ \\ ${ }^{1}$ Eastern Virginia Medical School, Norfolk, VA \\ 2 Tufts University School of Medicine, Boston, MA \\ ${ }^{3}$ University of Illinois School of Medicine, Chicago, IL
}

Teasing and bullying related to skin disease have been associated with depression, suicidal ideation, and social withdrawal. ${ }^{1}$ Psychological distress can further exacerbate skin conditions, initiating a vicious cycle of stress and disease. Specialized summer camps for children with skin disorders have been shown to help enhance quality of life. ${ }^{2}$

In 1993, the American Academy of Dermatology (AAD) created Camp Discovery, a one-week residential summer camp experience for children with chronic skin disorders. The entire experience is free of charge and many campers return to camp year after year to be with old friends and make new ones.

Due to the COVID-19 pandemic, camp was transformed into a virtual experience. Despite the incredible disappointment over not being able to come together in person, new opportunities emerged for children from different camp locations to meet and expand their networks of support. Virtual camp included old traditions such as cabin time, a time where campers would gather in their cabin groups and discuss the day's activities and play games, and new activities such as slime making, ice-cream making, and virtual Family Feud. The campers also had the opportunity to attend "gap week" sessions in between the traditional state-specific weeks. This afforded them ongoing fellowship throughout the summer months.

Not only is Camp Discovery beneficial for campers, but also volunteers. One study demonstrated that camp volunteerism increases empathy toward children with chronic conditions and provides volunteers with a sense of fulfillment. ${ }^{3}$

With the abrupt withdrawal of children from their school and social life, activities such as Camp Discovery may be helpful to restore these important facets of their lives, particularly for children with chronic skin disease. Despite the transition to a virtual format, the AAD's Camp Discovery continued to provide campers with a space to connect and enjoy each other's company.

Acknowledgments: The authors thank Susan Boiko, MD for editorial assistance in the preparation of the manuscript. The authors also thank Janine Mueller, who has coordinated and supported the American Academy of Dermatology Camp Discovery for many years.

Conflict of Interest Disclosures: None

Funding: None

Corresponding Author:

Katie A. O'Connell, MS

Eastern Virginia Medical School 


\section{References:}

1. Vivar KL, Kruse $\mathrm{L}$. The impact of pediatric skin disease on self-esteem. Int J Womens

Dermatol. 2018;4(1):27-31.

2. Wu J, Hogeling M. Impact of summer camps for children with chronic skin conditions [published online ahead of print, 2020 Aug 3]. J Am Acad Dermatol. 2020;S0190-9622(20)32309-4.

3. Bensimon J, Wiss K, Banker S. Impact of Camp Discovery volunteerism on provider burnout and empathy. J Am Acad Dermatol. 2020;83(2):636638. 